\title{
PHARMACOGNOSTIC STANDARDISATION AND CHROMATOGRAPHIC FINGERPRINTING OF LEAVES AND FRUITS OF ZANTHOXYLUM RHETSA
}

\author{
RASHMI MALLYA ${ }^{\mathrm{a}, \mathrm{b}^{*}}$, MILIND J BHITRE ${ }^{\mathrm{b}}$ \\ aSVKM's Dr. Bhanuben Nanavati College of Pharmacy, Gate No: 1 Mithibai College Campus, Vile Parle (W), Mumbai 400052, India, bC. U. \\ Shah College of Pharmacy, SNDT Women's University, Santacruz (West), Mumbai 400049, India \\ Email: rashmi.mallya@bncp.ac.in
}

Received: 01 Feb 2018 Revised and Accepted: 08 Mar 2018

\begin{abstract}
Objective: To conduct pharmacognostic standardisation and chromatographic fingerprinting of leaves and fruits of Zanthoxylum rhetsa.

Methods: The macroscopic, microscopic and physicochemical evaluation of the crude drugs were conducted as per I. P and WHO guidelines. The chromatographic fingerprint was also developed for the leaves and fruits.

Results: The microscopic characteristics of leaves exhibited anomocytic stomata, fibrovascular tissue, lignfied pericyclic fibers and pitted xylem vessels. The fruits exhibited pericarp, oil cells, stone cells, xylem and endosperm. The physicochemical analysis was also conducted. The leaf and fruit powders complied with WHO prescribed limits for microbial load NMT $1 \times 10^{5} \mathrm{CFU} / \mathrm{ml}$ and were found to be free from pathogenic organisms. The HPTLC fingerprint was established for methanol extract of leaves and fruits using Dichloromethane: chloroform: ethanol (4:4:1) as solvent and $10 \%$ methanolic sulphuric acid as spray reagent.
\end{abstract}

Conclusion: The present work provides referential information for the correct identification and standardisation of the plant.

Keywords: Zanthoxylum rhetsa, Fruit, Leaf, Microscopy, Fingerprint, Standardisation

(C) 2018 The Authors. Published by Innovare Academic Sciences Pvt Ltd. This is an open access article under the CC BY license (http://creativecommons.org/licenses/by/4.0/) DOI: http://dx.doi.org/10.22159/ijpps.2018v10i4.25089

\section{INTRODUCTION}

Since ancient times, natural products have been chief sources of medicines. The drugs that are used presently are obtained directly or indirectly from natural sources. According to WHO $80 \%$ of the population still relies on natural products for their health care needs. Nowadays, herbal materials and medicinal plants are often used as food, functional food, nutritional or dietary supplements. These require to be evaluated for their safety and efficacy and hence proper identification and standardization of the crude drug is very essential [1].

Zanthoxylum rhetsa (Syn: Z. budrunga, Z. limonella) family Rutaceae, also called as Indian prickly ash is found in India, Bangladesh, Burma and Himalayan region. In India, it is commonly found in the northeastern states and in eastern and Western Ghats of peninsular India [2]. The plant is routinely used as food and medicine. The shoots are consumed as food by indigenous people of northeast India and in many cuisines, fruits are used as a spice. Traditionally, the plant is employed for treatment of intestinal worms, urinary infection, heart troubles, toothache, asthma, bronchitis and rheumatism. Volatile oil of fruit known as "Mullilam oil" has been used as an antiseptic, anti-inflammatory, mosquito repellent, hypocholesterolemic and soothing agent for dental caries. The Naga tribe in the north-eastern region of India employ the leaf decoction in the treatment of intestinal worm infections and as insecticide [3].

Secondary metabolites such as alkaloids, lignans, coumarins, flavonoids, sterols, terpenoids and amides have been isolated from different parts of the plant exhibiting very good biological and pharmacological activities [4]. Phytochemical analysis of stem reveals the presence of alkaloids (limonellone, dictamine, nornitidine, rutaecarpine, acetonyldihydrochelerythrin, arnottianamide), lignans (-)-asarinin, coumarins (xanthoxyletin, osthol, scopoletin), aromatic amides (dihydroalatamide, (-)tembamide) and triterpenoids (lupeol). Isolated alkaloids, dictamine and tembamide showed good anticancer, antimicrobial and anti-HIV property respectively $[5,6]$. Alkaloids, arborine, dictamine and xanthoxyline, a substance with allelopathic effects was isolated from fruits [7]. The essential oil of fruits exhibited antioxidant, mosquito repellent, antiviral, antifungal and antitumour activity. Antimalarial properties were observed with the chloroform crude extract from fruits [8]and methanol extract of the seeds showed antinociceptive and antioxidant activities[9] Leaf exhibited the presence of alkaloids like pseudophrynamine, lunacridine 2-(29,49,69-trimethylheptenyl)-4-quinozolone. Flavonone from leaf had significant antimicrobial and cytotoxic property [10]. Leaf extract showed antiparasitic, in vitro thrombolytic and inhibitory action against MTCC 4030 strain of Klebsiella pneumonia [11-13].

As the plant has been widely used in food and therapeutics, there is a need for authentication and standardization of the plant material. Standardization ensures that a sample in a specified quantity exhibits same biological activity. It also ensures qualitative approval of the drug. Since an official monograph of the drug is not available, it is essential to provide referential information for correct identification and standardisation of plant material. Quality standards for plant material can be completely achieved by use modern chromatographic techniques and high-performance thin layer chromatography (HPTLC) is a popular method for analysis of herbal drugs $[14,15]$.

This study aims to conduct pharmacognostic standardisation and chromatographic fingerprinting of leaves and fruits of $Z$. rhetsa that can be useful for authentication and routine quality control of the plant material.

\section{MATERIALS AND METHODS}

Chemicals and reagents

Chemicals used for pharmacognostic standardisation were procured from SD Fine-Chem Ltd., India and were of laboratory grade. Analytical grade solvents for HPTLC were procured from Merck Specialities Pvt Ltd. Mumbai.

\section{Collection and authentication}

Zanthoxylum rhetsa fruits were collected in March-April 2016 and the leaves were collected in May-June 2016 from Karkala, Udupi 
district, Karnataka. The authentication of the sample was done by Dr. Rajendra Shinde, at Blatters Hebarium St. Xaviers College, Mumbai, Maharastra. A voucher specimen no BNCP/COG/VS-01 is preserved in our research laboratory for future reference. The fresh leaf and fruits were shade dried at room temperature and stored in well-closed containers until use.

\section{Morphological and microscopical analysis}

Morphological studies of the fruits and leaves of $Z$. rhetsa was conducted. For microscopic studies, hand sections were taken and cleared with chloral hydrate solution, stained with phloroglucinol and $\mathrm{HCl}$. The sections of the specimens were mounted in glycerine and examined microscopically. The leaf constants were calculated as per standard methods. [16] Photomicrographs of the sections were taken with the help of MOTIC photomicroscope provided with MOTIC IMAGE PLUS 2.0 software.

\section{Physicochemical and fluorescence analysis}

The physicochemical analysis like a loss on drying, total ash, acid insoluble ash, water soluble ash, water and ethanol soluble extractives were performed according to the methods prescribed in Indian Pharmacopoeia [17].

Fluorescence analysis of powdered drug was conducted as per reported methods. Powder of drug was treated with various reagents and was observed under daylight and U. V light. The colors and fluorescence (if any) observed were noted [18].

\section{Determination of microbial load}

Determination of total bacterial count, total fungal count and detection of pathogens $P$. aeruginosa, E. coli and $S$. aureus were performed as per WHO guidelines [19].

\section{HPTLC analysis}

The methanol extract of the samples was prepared using sonication process. Chromatographic separation of extracts of leaves and fruits were performed on $10 \mathrm{~cm} \times 10 \mathrm{~cm}$ Merck, TLC plate's silica gel $60 \mathrm{~F}$ 254. Samples of were applied by Linomat 5 at a concentration of 1.0 $\mu \mathrm{l}, 2.0 \mu \mathrm{l}$ and $5.0 \mu \mathrm{l}$ as $8 \mathrm{~mm}$ wide bands and $11.4 \mathrm{~mm}$ apart from the middle of bands by spray-on technique along with nitrogen gas supply for simultaneous drying of bands. Plates were developed to a distance of $70 \mathrm{~mm}$ at room temperature $\left(28 \pm 2{ }^{\circ} \mathrm{C}\right)$ with mobile phase in a CAMAG glass twin-trough chamber previously saturated with mobile phase vapour for $20 \mathrm{~min}$. After development, the plates were derivatised with reagent $10 \%$ methanolic sulphuric acid solution and dried at $105{ }^{\circ} \mathrm{C}$ for $3 \mathrm{~min}$, heated and scanned at 540 $\mathrm{nm}$ by CAMAG TLC scanner run on visioncats-serv, version 2.3.16286.1

\section{RESULTS}

\section{Morphological and microscopical analysis}

Macroscopically leaf presented a compound, paripinnate or imparipinnate structure $30-40 \mathrm{~cm}$ long containing 15-23 leaflets. The leaflets revealed opposite to sub-opposite, ovate to an elliptical shape, 7-13 cm long, 3-5 cm wide, with entire to glandular crenate margins. Leaflets exhibited rough surface with the unequal base. The fruits were present as follicles, globose, $7 \mathrm{~mm}$ in size with a single seed that was smooth, bluish-black and $5 \mathrm{~mm}$ size.

The transverse section of a leaf (fig. 1) exhibited dorsiventral nature. The midrib was hemispherical at the dorsal side and convex at the ventral side. The epidermis composed of single layer of cells was covered with a thin cuticle. The midrib had 2-4 layers of collenchyma above lower epidermis. Pith consisted of spongy parenchyma with lignified xylem arranged in vertical layers surrounded by phloem and schlerenchymatous layers of pericyclic fibers. The mesophyll had parenchyma and compactly arranged elongated palisade cells. The powder study of leaf exhibited anomoycytic type of stomata, unicellular trichomes, pitted xylem and lignified fibers.

Fruits revealed the presence of pericarp and seed. The pericarp consisted of epicarp, mesocarp and endocarp. Oil glands, vascular bundles and elongated stone cells were observed in mesocarp. Powder study of fruit showed presence of brown testa, elongated stone cells, fibers and endosperm [fig. 2].

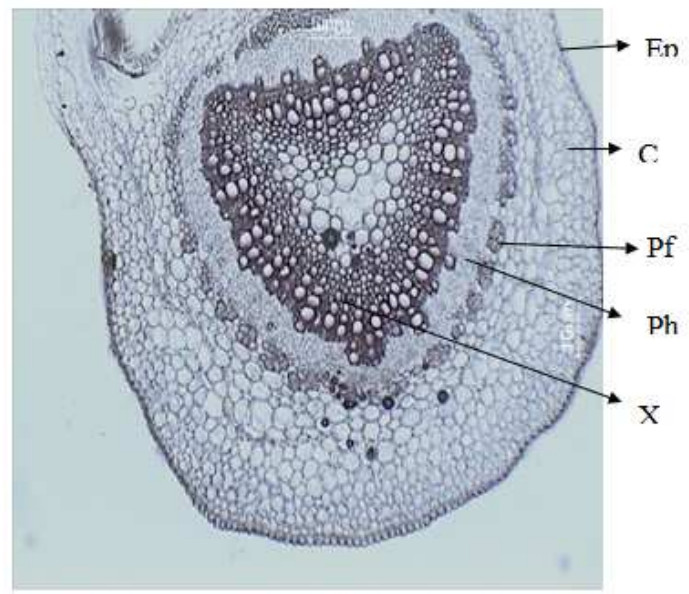

A

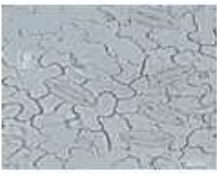

B

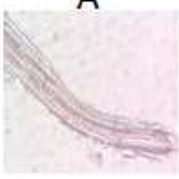

c

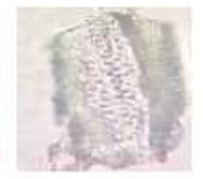

D
Fig. 1: Microscopy and powder study of leaf, A. T. S of Leaf (10x), B. Anomocytic stomata (40x), C. Lignified fibers (10x), D. Xylem vessels (10 x), Ep: Epidermis, Co: Collenchyma, Pf: Pericyclic fibers, Ph: Phloem, Xy: Xylem

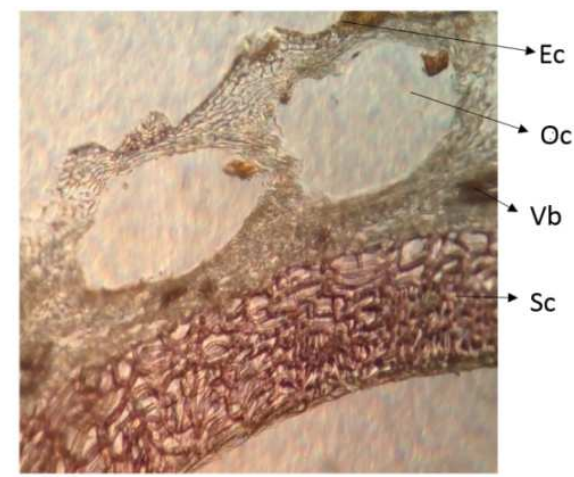

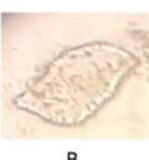

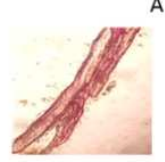

c

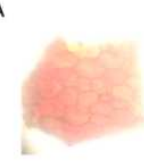

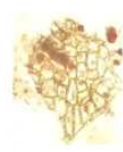

Fig. 2: Microscopy and powder study of fruit, A. T. S of pericarp (10x), B. Stone cells (10x), C. Lignified fibers (10x), D. Brown testa (10 x), E. Endosperm (10x), Ec: Epicarp, Oc: Oil cells, Vb: Vascular bundles, Sc-Stone cells

The proximate values of stomatal number, stomatal index, vein islet number, vein termination number and palisade ratio of the leaf is 75-81.25, 11.53-12, 12.5-18.75, 12.5 and 5-6 respectively.

\section{Physicochemical and fluorescence analysis}

Analysis of total ash, acid insoluble ash, water soluble ash, extractive value and loss on drying was done. Table 1 depicts the results of the 
physicochemical tests. Table 2 depicts the color and fluorescent pattern exhibited by chemical constituents of the plant in daylight or
UV. The powders when treated with various reagents showed different color reactions according to the chemical constituents present in them.

Table 1: Physicochemical analysis

\begin{tabular}{lll}
\hline Physicochemical parameter & Leaf values (\%) w/w & Fruit values (\%) w/w $^{\#}$ \\
\hline Total Ash value & $7.51 \pm 0.14$ & $6.72 \pm 0.22$ \\
Acid insoluble Ash & $0.352 \pm 0.21$ & $0.17 \pm 0.03$ \\
Water Soluble Ash & $2.49 \pm 0.20$ & $1.51 \pm 0.17$ \\
Loss on drying & $10.88 \pm 0.44$ & $12.48 \pm 0.33$ \\
Water Soluble extractive & $21.78 \pm 0.86$ & $15.03 \pm 0.85$ \\
Ethanol soluble extractive & $9.39 \pm 0.49$ & $12.09 \pm 0.36$ \\
\hline
\end{tabular}

\#Values are means of three independent analysis \pm standard deviation

Table 2: Fluorescence analysis

\begin{tabular}{llllll}
\hline Treatment & Leaf & & & Fruit & \\
\cline { 2 - 5 } & Day light & UV 254 & UV 365 & Day light & UV 254 \\
\hline Powder & Greenish & Black & Black & Brown & Black \\
Distilled water & Greenish & Black & Black & Brown & Black \\
$1 \mathrm{~N} \mathrm{NaOH}$ & Greenish & Black & Black & Brown & Greenish Yellow \\
$\mathrm{HCl}$ & Yellowish green & Dark blue & Black & Brown & Brown \\
$\mathrm{H}_{2} \mathrm{SO}_{4}$ & Brown & Bluish-black & Bluish-black & Blue & Greenish Yellow \\
$\mathrm{HNO}_{3}$ & Greenish black & Black & Black & Brown & Green \\
Chloroform & Dark green & Black & Black & Brown & Dlack \\
Acetic acid & Yellowish green & Yellow & Bluish-black & Black & Breen \\
Ferric chloride & Dark green & Yellow & Dark blue & Black & Brown \\
Ammonia & Green & Yellow & Bluish-black & Yellowish green & Black \\
Xylene & Brown & Dark blue & Brown & Reddish brown & Bluish-black \\
Iodine & Greenish yellow & Dark blue & Blue & Brown & Brown brown \\
Picric acid & Yellowish green & Dark blue & Brown & Brown & Ylack \\
\hline
\end{tabular}

\section{Determination of microbial load}

Total bacterial count and the total fungal count was found to be $0.56 \times$ $10^{2} \mathrm{CFU} / \mathrm{ml}$ and $0.33 \times 10^{5} \mathrm{CFU} / \mathrm{ml}$ respectively. Thus leaf and fruit powder complied with WHO prescribed limits for microbial load (NMT $\left.1 \times 10^{5} \mathrm{CFU} / \mathrm{ml}\right)$. The pathogenic microbes were found to be absent.

\section{HPTLC analysis}

HPTLC fingerprint of methanol extract of leaf and fruits [fig 3.] was developed using Dichloromethane: chloroform: ethanol (4:4:1 $\mathrm{v} / \mathrm{v} / \mathrm{v}$ ) as mobile phase and $10 \%$ methanolic sulphuric acid as spray reagent.
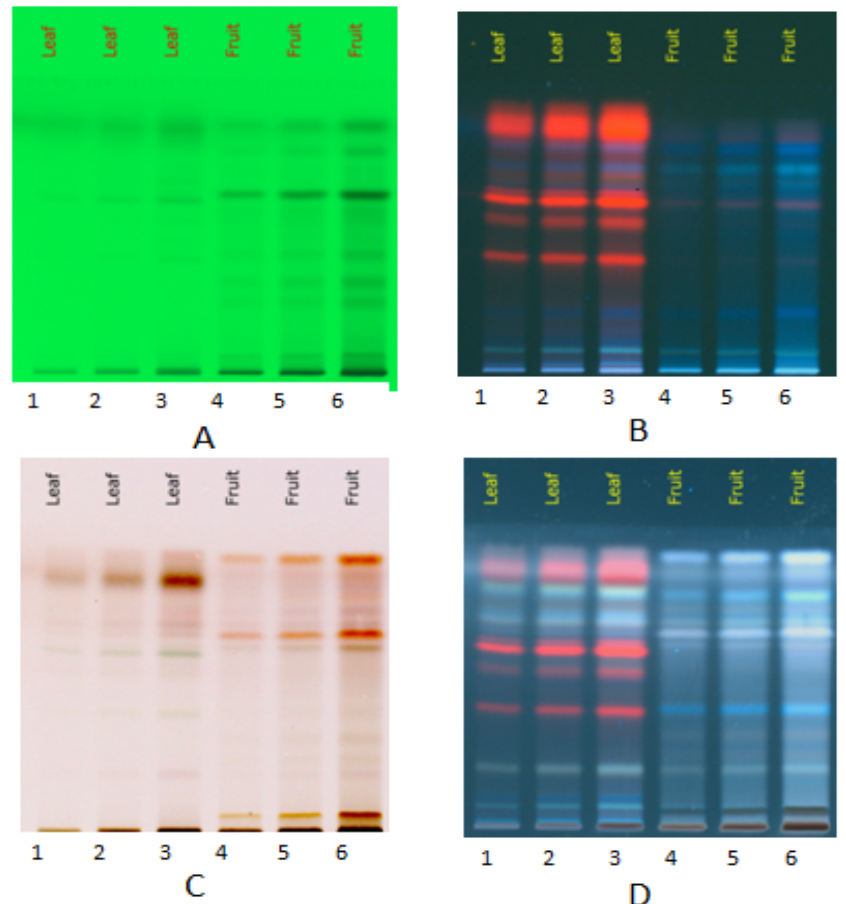

Fig. 3: Fingerprinting of extracts, (Track 1, 2, 3-1 $\mu \mathrm{l}, 2 \mu \mathrm{l}, 5 \mu \mathrm{l}$ of leaf extract; track 4,5,6-1 $\mu \mathrm{l}, 2 \mu \mathrm{l}, 5 \mu \mathrm{l}$ of fruit extract) A. UV $254 \mathrm{~nm}$ before derivatisation, B. UV $366 \mathrm{~nm}$ before derivatisation; C: $540 \mathrm{~nm}$ after derivatisation; D: UV $366 \mathrm{~nm}$ after derivatisation 
Methanol extract of leaves exhibited 6 spots with Rf value ranging from 0.019-0.963 and the constituent with Rf 0.96 was present at a highest concentration (70.62\%). Chromatogram of fruit methanol extract exhibited 9 spots with Rf ranging from 0.029-0.942 with a constituent of Rf 0.752 present in highest concentration (25.44\%). (fig. 4.)
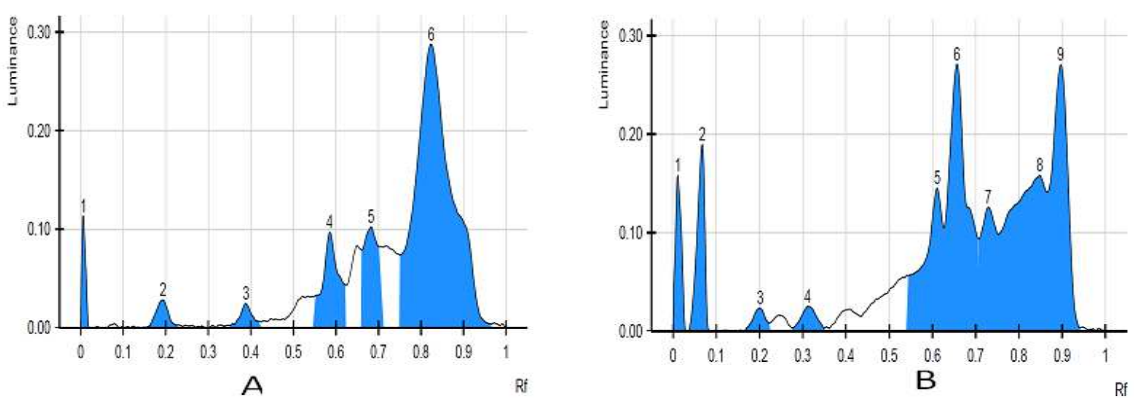

Fig. 4: HPTLC chromatogram of extracts after derivatisation at $540 \mathrm{~nm}$. A. Leaf B. fruit

\section{DISCUSSION}

As the leaves and fruits of $Z$. rhetsa have been widely used in food and therapeutics they can be an important source of lead molecules for drug development. It is essential to have the referential information for the authentication and pharmacognostic standardisation of the drug. Results of the present study provides the basis for identification and authentication of the leaves and fruits of $Z$. rhetsa.

Anomocytic stomata, unicellular trichomes and pericyclic fibres in leaf whereas stone cells and oil cells in fruits are the identification parameters for authentication. Qualitative information on the purity of drug is obtained by ash value, extractive value and loss on drying. Total ash reveals the presence or absence of inorganic matter such as metallic salts and silica and hence can be indicative of good preparation practices. The absence of silica or sand is indicated by the percentage of acid insoluble ash. The leaf contains a higher amount of water-soluble constituents in comparison to alcohol soluble constituents as indicated by the results of extractive value. The fruit contains an almost similar amount of water and alcohol-soluble constituents. The test for loss on drying determines both water and volatile matter in the crude drug. Although certain compounds are not fluorescent, they get converted to fluorescent derivatives by use of various chemical reagents like acids, bases, xylene and iodine. The color patterns produced in the analysis can be used as a standard fluorescent pattern for the quality evaluation of the plant. Compliance of microbial load to the WHO limits shows that various practices of collection, handling and production of this crude have been conducted properly. Chromatographic fingerprint developed helps to identify, check adulteration and determine the quality of the drug.

\section{CONCLUSION}

Standardisation of crude drugs is important for maintaining quality, purity and proper identification of the sample. Microscopic method helps in authentication of plants and physiochemical studies and HPTLC fingerprint help to get information on the quality of crude drugs. Thus present study helps in obtaining pharmacognostic standards for leaves and fruits of $Z$. rhetsa that will help in authentication, identifying adulteration and conducting routine quality control tests of crude drugs.

\section{AUTHORS CONTRIBUTIONS}

Both authors contributed equally to this manuscript.

\section{CONFLICTS OF INTERESTS}

\section{Declared none}

\section{REFERENCES}

1. Ekor M. The growing use of herbal medicines: issues relating to adverse reactions and challenges in monitoring safety. Front Pharmacol 2014:4:177.

2. Anonymous. The Wealth of India: Raw Materials and Industrial Products. Vol. XI. Publication and Information Directorate, CSIR, New Delhi; 1956. p. 22-3.
3. Quattrocchi U. CRC world dictionary of medicinal and poisonous plants: common names, scientific names, eponyms, synonyms, and etymology, CRC Press: India; 2012. p. 3650.

4. Patiño LO, Prieto RJ, Cuca SL. Zanthoxylum genus as a potential source of bioactive compounds. In Prof. Iraj R. editor. Bioactive compounds in phytomedicine. Intech Press; 2012.

5. Supabphol R, Tangjitjareonkun J. Chemical constituents and biological activities of Zanthoxylum limonella (Rutaceae): a review. Trop J Pharm Res 2014;13:2119-30.

6. Sreelekha M, Anto NP, Anto RJ, Shafi PM. Cytotoxicity of 6acetonyldihydro-chelerythrin, arnottianamide and 6-(2hydoxypropyl)-dihydro chelerythrine towards human cancer cell lines. Indian J Chem 2014;53B: 647-51.

7. Rahman MM, Islam MA, Khondkar P, Gray AI. Alkaloids and lignans from Zanthoxylum budrunga (Rutaceae). Biochem Syst Ecol 2005;33:91-6.

8. Charoenying P, Laosinwattana C, Phuwiwat W, Lomratsiri J. Biological activities of Zanthoxylum limonella alston fruit extracts. KMITL Sci J 2008;8:12-5.

9. Islam MK, Biswas NN, Saha S, Hossain H, Jahan IA, Khan TA, et al. Antinociceptive and antioxidant activity of Zanthoxylum budrunga wall (Rutaceae) seeds. Sci World J 2014. http://dx.doi.org/10.1155/2014/869537

10. Anwarul I, Abu S, Md Anwar-Ul, GRM Astaq MK, M Helal UB, Shah AB. A flavonone from leaves of Zanthoxylum budrunga: its in vitro antimicrobial activity and cytotoxic evaluation. J Med Sci 2001;1:209-13.

11. Yadav AK, Tangpu V. Therapeutic efficacy of Zanthoxylum rhetsa DC extract against experimental Hymenolepis diminuta (Cestoda) infections in rats. J Parasit Dis 2009;33:42-7.

12. Shaik G, Sujatha N, Mehar SK. Medicinal plants as a source of antibacterial agents to counter Klebsiella pneumoniae. J Appl Pharm Sci 2014;4:135-47.

13. Azad AK, Ohidul I, Rima E, Mohaiminul I, Chand S, Jeb-Un N, et al. Phytochemical screening and in vitro thrombolytic activity of methanolic leaf extract of Zanthoxylum rhetsa. J Pharm Sci Res 2015;7:302-4.

14. Yamunadevi M, Wesely EG, Johnson M. Chromatographic fingerprint studies on saponins of Aerva lanata (1.) juss. ex schultes by using HPTLC. Int J Curr Pharm Res 2018;4:52-7.

15. Pallavi Y, Hemalatha KPJ. Phytochemical studies and highperformance thin-layer chromatography analysis of Calamus rotang linn leaf extracts. Asian J Pharm Clin Res 2018;11:269-75.

16. Wallis TE. Practical pharmacognosy. London; J. and A. Churchill Ltd; 1953. p. 139.

17. Anonymous. Indian Pharmacopoeia. Vol. 2. Ministry of Health and Family Welfare, Government of India, Controller of Publications: New Delhi; 1996.

18. Nagulan S, Kumar SR. Phytochemical, physicochemical and fluorescence analysis of leaf extract of Syzigium calophyllofolium Walp. Asian J Pharm Clin Res 2016;9:276.

19. WHO. Quality control methods for medicinal plant materials. Geneva: World Health Organization; 1992. 